\title{
Uncovering the unknown
}

Citation for published version (APA):

Ramani, S., Konings, K., Mann, K. V., \& van der Vleuten, C. (2017). Uncovering the unknown: A grounded theory study exploring the impact of self-awareness on the culture of feedback in residency education. Medical Teacher, 39(10), 1065-1073. https://doi.org/10.1080/0142159X.2017.1353071

Document status and date:

Published: 01/01/2017

DOI:

10.1080/0142159X.2017.1353071

Document Version:

Publisher's PDF, also known as Version of record

Document license:
Taverne

Please check the document version of this publication:

- A submitted manuscript is the version of the article upon submission and before peer-review. There can be important differences between the submitted version and the official published version of record.

People interested in the research are advised to contact the author for the final version of the publication, or visit the DOI to the publisher's website.

- The final author version and the galley proof are versions of the publication after peer review.

- The final published version features the final layout of the paper including the volume, issue and page numbers.

Link to publication

\footnotetext{
General rights rights.

- You may freely distribute the URL identifying the publication in the public portal. please follow below link for the End User Agreement:

www.umlib.nl/taverne-license

Take down policy

If you believe that this document breaches copyright please contact us at:

repository@maastrichtuniversity.nl

providing details and we will investigate your claim.
}

Copyright and moral rights for the publications made accessible in the public portal are retained by the authors and/or other copyright owners and it is a condition of accessing publications that users recognise and abide by the legal requirements associated with these

- Users may download and print one copy of any publication from the public portal for the purpose of private study or research.

- You may not further distribute the material or use it for any profit-making activity or commercial gain

If the publication is distributed under the terms of Article $25 \mathrm{fa}$ of the Dutch Copyright Act, indicated by the "Taverne" license above, 


\section{Uncovering the unknown: A grounded theory study exploring the impact of self-awareness on the culture of feedback in residency education}

\section{Subha Ramani, Karen Könings, Karen V. Mann \& Cees van der Vleuten}

To cite this article: Subha Ramani, Karen Könings, Karen V. Mann \& Cees van der Vleuten (2017) Uncovering the unknown: A grounded theory study exploring the impact of self-awareness on the culture of feedback in residency education, Medical Teacher, 39:10, 1065-1073, DOI: 10.1080/0142159X.2017.1353071

To link to this article: https://doi.org/10.1080/0142159X.2017.1353071

Published online: 25 Jul 2017.

Submit your article to this journal

Џll Article views: 2011

Q View related articles $\sqsubset$

View Crossmark data \lceil

Citing articles: 14 View citing articles $\asymp$ 


\title{
Uncovering the unknown: A grounded theory study exploring the impact of self-awareness on the culture of feedback in residency education
}

\author{
Subha Ramani ${ }^{a}$, Karen Könings ${ }^{b}$, Karen V. Mann ${ }^{c}$ and Cees van der Vleuten ${ }^{b}$ \\ ${ }^{a}$ Department of Medicine, Brigham and Women's Hospital, Harvard Medical School, Boston, MA, USA; ${ }^{b}$ School of Health Professions \\ Education, Maastricht University, Maastricht, The Netherlands; 'Dalhousie University, Halifax, Canada
}

\begin{abstract}
Aim: Self-assessment and reflection are essential for meaningful feedback. We aimed to explore whether the well-known Johari window model of self-awareness could guide feedback conversations between faculty and residents and enhance the institutional feedback culture.

Methods: We had previously explored perceptions of residents and faculty regarding sociocultural factors impacting feedback. We re-analyzed data targeting themes related to self-assessment, reflection, feedback seeking and acceptance, aiming to generate individual and institutional feedback strategies applicable to each quadrant of the window.

Results: We identified the following themes for each quadrant: (1) Behaviors known to self and others - Validating the known; (2) Behaviors unknown to self but known to others - Accepting the blind; (3) Behaviors known to self and unknown to others - Disclosure of hidden; and (4) Behaviors unknown to self and others - Uncovering the unknown. Normalizing self-disclosure of limitations, encouraging feedback seeking, training in nonjudgmental feedback and providing opportunities for longitudinal relationships could promote self-awareness, ultimately expanding the "open" quadrant of the Johari window.

Conclusions: The Johari window, a model of self-awareness in interpersonal communications, could provide a robust framework for individuals to improve their feedback conversations and institutions to design feedback initiatives that enhance its quality and impact.
\end{abstract}

\section{Introduction}

Effective feedback, integral to continuing professional development, needs to be credible and informed by selfreflection to facilitate performance improvement (Cantillon and Sargeant 2008; Sargeant et al. 2008a, 2009; Delva et al. 2011; Boud 2015). Feedback exchanges also need to address factors such as self-efficacy and autonomy which could impact internal motivation and lead to loss of "face" (Ten Cate 2013; Ramani et al. 2017). Accurate self-calibration of performance requires reflection in and on action, self-assessment and feedback from others (Boud 1995; Eva and Regehr 2007, 2008). Thus, changing the institutional feedback culture would require concerted efforts to stimulate these strategies (Sargeant 2008; Sargeant et al. 2008b, 2009; Sargeant 2012). A framework such as the Johari window could guide educators and institutions in establishing a learning culture that actively encourages self-awareness, thereby raising the credibility and acceptability of feedback and promoting commitment to behavior change. Below, we describe how the Johari window could be used to incorporate self-assessment and reflection into feedback conversations.

The Johari window is a psychological matrix developed by Joseph Luft and Harry Ingham in 1955, to enable awareness and understanding of own behaviors, feelings and motivation during interpersonal interactions (Luft 1969). The model also applies to person-environment interactions and explains the role of self-awareness in professional development. There are four quadrants, each depicting a

\section{Practice points}

- The impact of feedback should be determined by its acceptance and incorporation by feedback receivers and subsequent behavior change

- Unguided self-assessment is likely to lead to inaccurate calibration of own performance

- Informed self-assessment and facilitated reflection should be considered integral elements of feedback conversations

- The Johari window, a framework for self-awareness in interpersonal communications, can be a useful model to structure the content of feedback conversations and design feedback training

- Individual and institutional pedagogical strategies can expand the "open" space and shrink the "blind" and "hidden" spaces, and gradually uncover the "unknown" quadrant

different level of self-awareness: (1) known to self and others (open), (2) unknown to self but known to others (blind), (3) known to self and unknown to others (hidden), and (4) unknown to self and others (unknown) (Numerof 1979; Sutherland 1995; Verklan 2007). The Johari window has been infrequently used in medical education. Since feedback conversations are complex interactions between two persons, or between persons and their work or learning environment, we propose this matrix as an effective

CONTACT Subha Ramani sramani@bwh.harvard.edu $\Theta$ Director, Scholars in Medical Education Track, Internal Medicine Residency Program, Brigham and Women's Hospital, Harvard Medical School, 75 Francis Street, Boston, MA 02115, USA

(C) 2017 Informa UK Limited, trading as Taylor \& Francis Group 
framework to guide systematic inquiries into the culture of feedback, feedback seeking, receptivity and impact on performance. In the next section, self-assessment and reflection are described as two important pedagogical strategies relevant to the Johari model and essential to the effective exchange of feedback.

The first strategy is self-assessment, traditionally viewed as an unguided, self-generated strategy to assess one's own abilities. However, professionals' ability to self-assess has been reported as less accurate than external observations, with suboptimal performers tending to overestimate their competence due to lack of insight into their errors (Kruger and Dunning 1999; Dunning et al. 2004; Eva and Regehr 2005; Davis et al. 2006; Ehrlinger et al. 2008; Sargeant et al. 2008b). This incongruence is amplified when data from others conflict with impressions of self or if learners view the source as lacking credibility (Sargeant et al. 2008a; Mann et al. 2011). More recent definitions of self-assessment strongly emphasize inclusion of data from external sources. Boud (1995) describes self-assessment as a process that requires internal and external data about one's performance and comparing these with a standard to make a judgment about one's performance. Mann et al. (2011) coined the term informed self-assessment, defining it as the incorporation of internal and external data into selfappraisal. The term self-directed assessment seeking refers to the pedagogical activity of looking outward for formative and summative assessments of one's current level of performance (Eva and Regehr 2008). These descriptions of self-assessment as an interactive rather than individual strategy are more relevant to feedback seeking, acceptance and impact on behavior.

The second important strategy is reflection, which can be categorized as reflective learning and practice. Reflective learning refers to critical thinking and analysis of own experience and performance to inform growth in knowledge, skills and attitudes (Moon 2004; Chaffey et al. 2012; Hayton et al. 2015). Reflective practice, a core tenet for healthcare professionals, is the ability to reflect on one's actions to enable continuing professional development (Schoin 1983). Reflection in action is the analysis of one's performance during the event potentially leading to immediate and beneficial behavior change, while reflection on action is the review of one's performance after the event to change future behavior. Boud et al. state that: "Reflection is an important human activity in which people recapture their experience, think about it, mull it over and evaluate it. It is this working with experience that is important in learning" (Boud et al. 1985). Reflection has also been described as the link between receiving and assimilating feedback (Sargeant et al. 2009). Provision of feedback is thought to stimulate a reflective process among receivers which can be instrumental to acceptance and incorporation of data.

While informed self-assessment and facilitated reflection of performance have been the subject of many recent research reports, how these strategies influence feedback conversations between faculty and residents is largely unknown. Resident and faculty perceptions on the impact of institutional culture on these pedagogical strategies have also not been studied. Using qualitative methodology, we had previously conducted two studies in open-ended explorations of (1) perspectives of residents on the value of, barriers to, and best practices for feedback (Ramani et al. 2017), and (2) perspectives of residents and clinical teachers on the institutional feedback culture, feedback seeking, receptivity and bidirectional feedback (manuscript under review). Key results from the previous studies indicated that institutional culture had a significant impact on the content and credibility of feedback exchanges. Residents and faculty also reported that the institutional culture of politeness was a barrier to honest, especially constructive feedback. In this study, we performed a focused in-depth exploration of factors impacting feedback, solely through the lens of the Johari window. Thus, we only targeted themes related to self-assessment, reflection, feedback seeking and acceptance. Specifically, we aimed to discover individual and institutional strategies that could be applied to each quadrant of the window to enhance the culture of feedback. We describe how self-awareness, feedback seeking and receptivity could interact to inform learners about their performance, and the role of the institution in implementing strategies to enhance the culture of feedback.

\section{Methods}

Data from two previous studies were re-analyzed using the Johari framework. The study setting, sampling and data collection summarize the methods for studies 1 and 2, and no new participants were recruited for this study.

\section{Study setting}

The study was conducted at a large, urban training program with approximately 160 residents. Residents on a 3to 4-year training track work in inpatient and outpatient settings. Ward teams consist of one or two postgraduate year (PGY) 2, 3 or 4 residents; two or three PGY1 residents; one or two attending physicians; and one or two medical students, who mostly work together for two weeks. Only in continuity clinics do residents have a longitudinal faculty supervisor. The quality of feedback would be variable as faculty level and experience in teaching vary. The institution outlines expectations for feedback but does not mandate feedback training.

\section{Qualitative approach and sampling}

A constructivist grounded theory approach, appropriate for hypothesis generation, was used to explore participant views on the role of feedback seeking, informed self-assessment and reflection on clinical performance and professional growth (Kennedy and Lingard 2006; Watling and Lingard 2012; Charmaz 2014). Using a purposive sampling strategy, we recruited residents and faculty for focus group discussions. Purposive sampling strategies target representative groups, in this case residents who rotate on inpatient and continuity clinic settings and generalist faculty who provide most of the clinical supervision and teaching (Creswell and Creswell 2013; Ramani and Mann 2016). All prospective participants received email invitations describing the purpose of the study, emphasizing that participation was voluntary and ensuring confidentiality 
Table 1. Subjects and focus group trigger questions in studies 1 and 2.

\begin{tabular}{|c|c|c|}
\hline Study & Subjects & Trigger questions \\
\hline 1 & 38 residents & $\begin{array}{l}\text { 1. Does feedback provided by faculty facilitate performance improvement? } \\
\text { 2. What are the strengths and weaknesses of the current feedback system in our residency program? } \\
\text { 3. Can you describe challenges encountered when you give or receive feedback? } \\
\text { 4. Can you suggest strategies to improve the feedback culture in our department? }\end{array}$ \\
\hline 2 & $\begin{array}{l}29 \text { residents } \\
22 \text { faculty }\end{array}$ & $\begin{array}{l}\text { 1. Feedback culture: } \\
\text { When the term feedback culture is used, what does it mean to you? } \\
\text { How would you describe our institutional feedback culture? } \\
\text { Can you suggest strategies to enhance the feedback culture in our department? } \\
\text { In previous discussions, residents had expressed that our culture of politeness } \\
\text { inhibits meaningful feedback, what are your opinions regarding this? } \\
\text { 2. Feedback seeking and receptivity: } \\
\text { How important is feedback seeking behavior in obtaining meaningful feedback? } \\
\text { Do you seek feedback? If yes, was it effective? If no, what are the reasons for not seeking it? } \\
\text { What factors could increase receptivity to constructive feedback? } \\
\text { 3. Bidirectional feedback: } \\
\text { In your opinion, is bidirectional feedback important? } \\
\text { How often do you give feedback to seniors (faculty or residents)? } \\
\text { How can we encourage bidirectional feedback? }\end{array}$ \\
\hline
\end{tabular}

of opinions. Verbal consent was obtained from participants, with the opportunity to opt out at any point.

\section{Data collection}

The primary data collection was through focus group discussions supplemented by field notes. Focus groups were facilitated by the first author SR, a faculty trained in qualitative methodology, assisted by a research assistant who monitored the discussions and debriefed with the interviewer.

Open-ended questions explored participant opinions on the institutional feedback culture, factors impacting feedback seeking, receptivity and bidirectional feedback. A total of nine resident focus group discussions (four for study 1 and five for study 2) were conducted between December 2013 and May 2016; all groups consisted of PGY1, 2 and 3 residents. Three focus groups with general medicine faculty (continuity clinic preceptors and inpatient attendings) were conducted between June and October 2016 (study 2). All focus group discussions were 60 minutes in duration. Openended questions, discussed in advance by the research team, were used as triggers to initiate conversations, and clarification and further elaboration were sought as required (Table 1 ).

\section{Data analysis}

Eleven focus group transcripts provided data for a new framework-based qualitative analysis, using the Johari window model. A conceptual thematic analysis was carried out to explore how our findings aligned with or challenged constructs for each quadrant of the Johari window. Only themes related to self-assessment and reflection and applicable to the framework were identified. A constant comparative approach required for grounded theory research was utilized (Patton 2002; Kennedy and Lingard 2006; Creswell 2012; Watling and Lingard 2012; Charmaz 2014). Two investigators independently performed a thematic analysis to identify major themes grounded in participant narratives using NVivo software. Emerging themes were discussed with the entire research team, and ambiguities or disagreements in coding and generation of themes were resolved by consensus at research team meetings.

To ensure reflexivity, we reflected on and acknowledged any influence of researchers in their approach to sampling, data collection and analysis (Watt 2007; Watling and Lingard 2012). The lead author (SR), a faculty in the Department of Medicine, is not responsible for promotion or graduation decisions for residents or in a position of power over faculty. Her collaborators are nonphysicians, not affiliated with the institution where the research was conducted, and experts in health professions education research $(\mathrm{CV}, \mathrm{KK})$. The team also included two research assistants, one of whom observed the focus groups and took field notes and the other participated in independent data analysis (LW, EP). Each transcript was reviewed to ensure that questions remained open-ended and allowed for expression of a wide range of opinions.

\section{Ethical approval}

The study was granted exempt status by the Partners Institutional Review Board, the review board for Brigham and Women's Hospital (Protocol\#2013P002270/BWH).

\section{Results}

A total of 67 residents participated in nine focus group discussions and 22 generalist faculty participated in three focus group discussions. These data were collected for studies 1 and 2 as described previously. In our new thematic analysis based solely on the framework of the Johari window, we identified the following themes most applicable to each quadrant:

1. Validating the known: Quadrant 1-Behaviors known to self and others

2. Accepting the blind: Quadrant 2-Behaviors unknown to self but known to others

3. Disclosure of hidden: Quadrant 3-Behaviors known to self but unknown to others

4. Uncovering the unknown: Quadrant 4-Behaviors unknown to self and others

\section{Validating the known}

The "known" quadrant refers to competency domains or behaviors known to the resident as well as their supervising faculty and peers. Reviewing these areas during feedback conversations validates the feedback receiver that their selfassessment is accurate and reinforces that their 
performance improvement plans are on target. Reinforcing good clinical habits can ensure that the resident will continue to engage in such behavior.

Feedback isn't code for criticism. It means, how are you doing? It could be good; it could be bad. The absence of feedback is bad ... It doesn't have to be critical to be accurate. (R)

Sometimes you just want to hear, 'yes, you are where you're supposed to be.' Sometimes that's all you need to know. (R)

Feedback is useful not only to identify weaknesses but also to provide reassurance that one is on the right track. $(F)$

While known behaviors include strengths and deficiencies, faculty emphasized the role of positive feedback in establishing trust and setting the tone for ongoing conversations.

I think lots of positive feedback is important to developing their trust. If they only notice that you're picking out the bad stuff, they are going to think you're not really on their side. You need to catch them doing something right. Have them be called out for an excellent job so they get used to the idea that you're not out to get them. You want to help them and reinforce the good things that they're doing as well as help with the bad. (F)

Residents and faculty stated that discussing known behaviors is important to assess the accuracy of self-assessment, validate and reinforce strengths.

\section{Accepting the blind}

The "blind" quadrant refers to areas of performance unknown to the resident but evident to supervising faculty and peers. It is likely easier to discuss strengths, but the challenge arises when the blind area involves constructive feedback on underperformance, often skipped to avoid hurting receivers' feelings. Engaging in active feedback seeking, grounding feedback conversations in learning goals and facilitating performance improvement plans could make it more palatable to accept constructive comments.

I think that's (the responsibility) on the receiver a little bit. You have to say I'm not interested in hearing the things you think I'm doing great at, because that'll make me feel good, but that's not the point of this. It's to grow. (R)

To say you're not going to hurt my feelings. I want to know what things I can really improve on and how to do it. Then to push people when you feel like they're sugar-coating things a little bit. (R)

We're not always focused on giving feedback or thinking about what each resident needs the feedback on, would be useful to have this information. (F)

Faculty expressed that modeling feedback-seeking behavior and demonstrating their own efforts at ongoing professional growth could encourage residents to do the same and enhance their acceptance of constructive feedback.

If you show them that you're trying to seek active feedback and continuing to learn, maybe the constructive feedback you're providing also carries a bit more weight. (F)

I always ask for feedback genuinely and say, "I'm always striving to improve my attending skills, my teaching skills, so I'm asking you for honest feedback." (F)
Additionally, it was suggested that feedback training should not just focus on the skills of giving, but also on receiving and accepting it.

I think we should be told at the beginning, how you seek out and how you react to the feedback that you're given. If you're defensive, if you don't push people to say tell me what I could be doing a better job at, it's very easy to get through residency without anybody ever telling you those things. (R)

Just teach people to seek out constructive criticism, but criticism so that they grow. (F)

The comparison to sports coaching as well as parenting was brought up as strategies to defuse emotion and avoid the implication that the comments were an attack on the person.

As specific as you can get, it takes the emotional valence out of it. Giving tips on someone's golf swing is a lot easier than telling them that they are lacking as a person. It's also more actionable .... in general you're separating the person from the behaviour, which is something you learn from parenting all the time. (R)

Overall, participants indicated that strategies to encourage acceptance of constructive feedback pertaining to skills in the blind quadrant include active feedback seeking, training in feedback seeking and receiving, and a coaching culture similar to that seen in sports.

\section{Disclosure of hidden}

The "hidden" quadrant comprises what is known to the resident but not to faculty or peers and therefore requires disclosure by the resident. While expectations about weekly feedback exchanges were communicated regularly, participants stated that performance goals were rarely discussed, resulting in conversations not guided by self-disclosed goals, fears or limitations.

\begin{abstract}
I have had interns who pick one or two areas of weakness that they want to focus on for that rotation. I found that incredibly helpful in terms of the entire rotation. I think that can do tons in terms of making the whole feedback experience much more useful. (R)
\end{abstract}

It helps if you ask the person you're working with, is there anything in particular you're working on or trying to get better at? That way, it doesn't feel like it's coming out of nowhere. It feels like 'okay, I asked you to watch me in this particular domain and see how I'm doing'. (F)

The credibility of feedback could be influenced by the relationship between the feedback provider and receiver. Residents may be willing to disclose their goals, and limitations to those they trust, allowing for more focused and actionable feedback. Positive relationships can also stimulate more performance observation and make the feedback data more acceptable.

The most useful relationship was with my clinic preceptor who knows me best as a clinician and has given me the most formative feedback. I think they go together. Because I feel like she knows me so well, I really value what she says. It has a lot of merit. I think I've been very lucky in that sense. (R)

How you evaluate someone, or think about someone growing, is really the question. Any sort of relationship that happens over time offers better opportunities for feedback. (R) 
The more time the person that's getting feedback spends with you, the better able they should be to give you that feedback. The less the receiver can say, in their head, they didn't see me in this situation. How do they know what I'm doing here? (F)

Development of trusting and longitudinal relationships between residents and faculty was thought to be important to allow for disclosure of performance goals, fears and insecurities.

\section{Uncovering the unknown}

The "unknown" quadrant refers to domains unknown to the resident as well as supervising faculty. Therefore, seeking feedback from peers and other staff could be helpful. Residents indicated that their near peers provided feedback on very different skills than faculty and wished peer-peer feedback conversations occurred more frequently. Some inpatient attendings emphasized the importance of feedback from nonphysician team members whose perceptions of physician-patient interactions and teamwork are likely to be different and valuable.

I wish interns give more feedback on the teaching, running rounds, how supportive I am, how it is working with us, the nitty-gritty. And it's different feedback than I would get from an attending. (R)

I think the nurses, case managers and other team members should also be evaluating residents from a multidisciplinary team standpoint. They provide informal feedback on different skills than we do-professionalism, teamwork, interpersonal skills etc.(F)

Training in the skills of giving feedback, both top-down and bottom-up, was considered important by residents and faculty. Effective techniques to providing constructive feedback emphasizing the goal of mutual professional growth were suggested. Residents who had participated in courses at the business school stated that medical education could borrow methods of feedback training from outside the profession.

I think formal feedback teaching with the goal being how to give negative feedback would be a very good thing. (F)

Attendings are being trained to be educators and deserve a session on how to give good feedback... the concept of [trainee] growth needs to be ingrained in the culture. (R)

Go to McKenzie or Google. I'm sure they have a great apparatus for giving feedback, these companies focus on parallel feedback and top-down feedback. There are ways of teaching feedback in an efficient way so you show them how to do it before they start. (R)

Participant statements indicate that unknown behaviors could come to light through frequent performance observation, multisource feedback and feedback training that emphasizes professional growth.

\section{Discussion}

In this study, we sought to explore perceptions of residents and faculty to help us determine the fit between sociocultural factors that impact feedback and a psychological model that emphasizes self-awareness in professional development. Based on our findings, we believe that the
Johari window model can effectively guide feedback conversations between faculty and residents, and the design of feedback initiatives by institutions. Originally described as a model of interpersonal communication and later adapted for leadership, teamwork, teaching skills, etc., the model comprises self-awareness and perception of self as core components (Numerof 1979; Sutherland 1995; Verklan 2007). Thus far, no studies have been published on the application or utility of this model in feedback conversations in medical education. The perception of self includes self-assessment and reflection, both of which can play a significant role in influencing the quality of feedback conversations. Stimulating these pedagogical strategies could influence behavior change and performance improvement, through learners' willingness to self-discover strengths and weaknesses, feedback-seeking behavior and receptivity to multisource feedback. Our data suggest that both residents and faculty view effective feedback as an interpersonal communication facilitated or inhibited by the institutional culture, rather than a unidirectional top-down process. Additionally, the clinical environment is one where patient care is delivered by teams, where perception of self and perception of one's behaviors by other team members are essential for optimal functioning.

In the next sections, we describe feedback strategies to potentially expand the "open" quadrant and shrink the "hidden," "blind" and "unknown" quadrants, as depicted in Figure 1. Under each quadrant, we have listed strategies for individual feedback providers and receivers, followed by institutional initiatives that could maximize professional growth.

The "open" quadrant enables individual professionals and teams to be most productive. Strengths as well as deficiencies need to be discussed to stimulate a growth mindset. For feedback providers, encouraging reflection and inviting self-assessment from receivers can expand this quadrant. However, research suggests that most people tend to possess inflated self-assessments as they pay more attention to positive data in reconstructing experiences (Davis et al. 2006; Eva and Regehr 2008); thus, unguided reflection and self-assessment can lead feedback receivers to inaccurately calibrate their performance level (Kruger and Dunning 1999). Self-reflection is more accurate when it incorporates performance data from external sources (Boud 1995; Epstein and Hundert 2002; Eva and Regehr 2008; Sargeant et al. 2009; Mann et al. 2011; Sargeant et al. 2015). Sargeant et al. (2015) recently described the R2C2 model, a facilitated reflective performance feedback model, comprising the following steps: building a relationship, exploring reactions to performance data, exploring learners' understanding of the content of feedback and coaching for performance change. Self-directed assessment seeking can be useful not only to validate perception of strengths and agreement on areas needing improvement, but also to assess accuracy of residents' self-awareness (Eva and Regehr 2008). Institutional leaders have a major role in promoting a culture where informed self-assessment becomes the norm, and providing training on these skills, thereby enlarging the "open" quadrant for individuals and teams. Additionally, faculty supervisors should present frequent, affirmative feedback on performance along with a road map detailing where learners need to be at different stages and a plan to get there. These strategies can also address 
Known to self

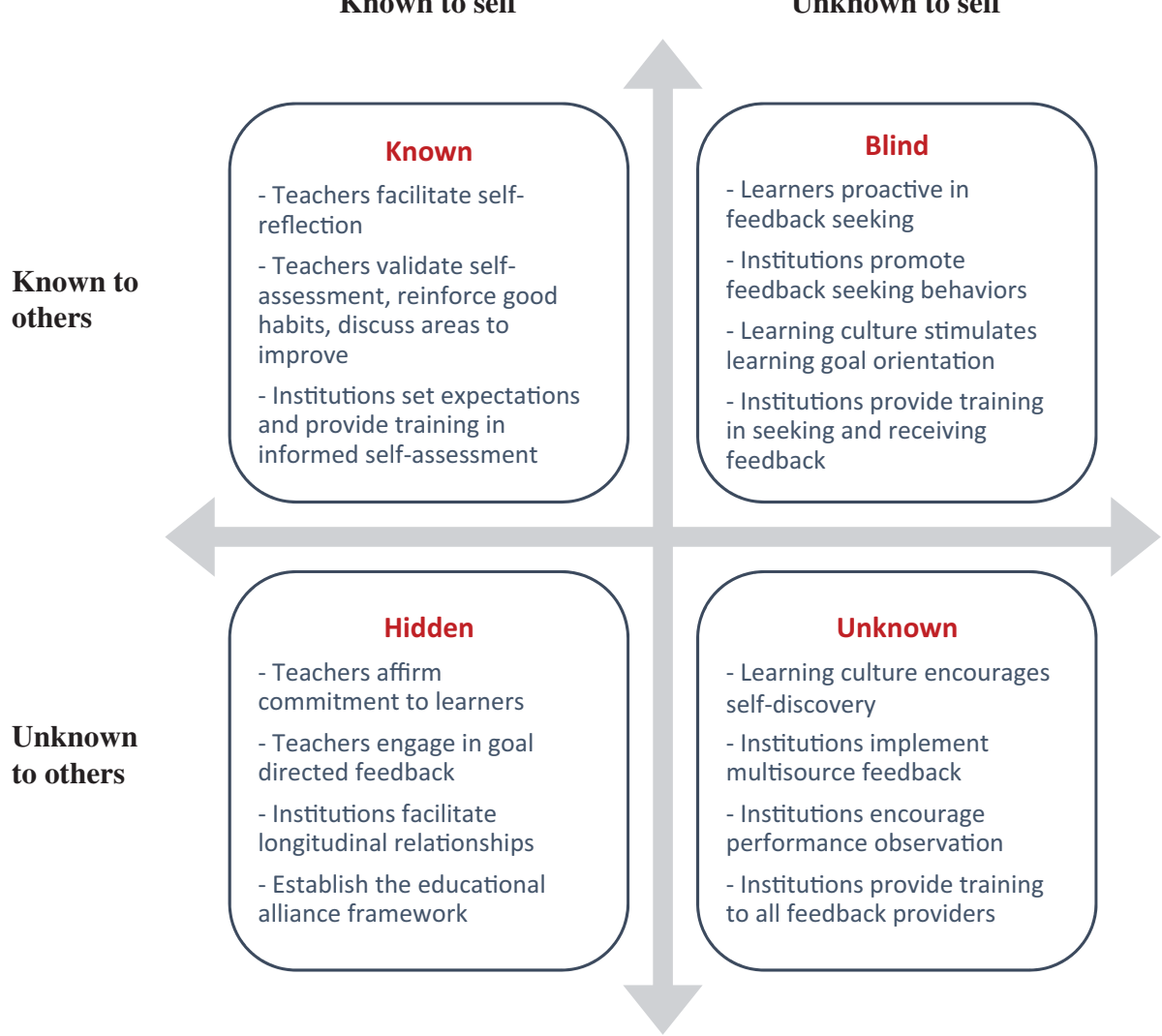

Figure 1. The Johari window and the culture of feedback. The four quadrants of the Johari window list strategies that individuals and institutions can use to enhance self-awareness and impact of feedback, thereby optimizing the size of each quadrant.

learners' sense of competence, relatedness and autonomy, needs that are crucial in residency education (Schumacher et al. 2013; Ramani et al. 2017).

The "blind" quadrant arises out of ignorance about one's behaviors and performance. A multipronged approach is needed to shrink this space. Learners can gain awareness of their blind spots through active feedback seeking, defined as one's conscious efforts to determine adequacy of performance in attaining required learning goals (Crommelinck and Anseel 2013). Since feedback-seeking behavior can be driven by the desire for useful information, to enhance one's ego, or maintain a positive image, it can be influenced by goal orientation of individuals (VandeWalle et al. 2000; VandeWalle et al. 2001; Teunissen et al. 2009). Trainees with a performance goal orientation, focus on good performance and creating a good impression, may avoid feedback that could reveal limitations and threaten their image. Those with a learning goal orientation, focus on gaining new knowledge and skills, are more likely to engage in feedback seeking to correct deficiencies and gain mastery in their field. Feedback seeking can also be impacted by the attending physician's supervisory style and interpersonal skills (Teunissen et al. 2009; Bok et al. 2013). Institutions need to establish a learning culture that actively promotes feedback-seeking behavior, emphasize learning goal rather than performance goal orientation among its trainees and staff, communicate these as clear expectations and provide feedback training that includes strategies for seeking, receiving and incorporating feedback (Teunissen and Bok 2013).

The "hidden" quadrant represents information, feelings, fears, agendas or context that a resident may hesitate to reveal to supervising faculty or peers. Disclosure is necessary to narrow this space, though how much to reveal would depend on the person, the trust and relationship with others. Many potential negative effects of rapid transitions and short rotations in clinical medicine have been described including inability of trainees and faculty to establish trusting educational or working relationships, lack of knowledge about each other's motivation, commitment or goals, and lack of a shared mental model of performance appraisal and expectations for feedback (Bernabeo et al. 2011; Holmboe et al. 2011; Sargeant et al. 2011; Watling 2014a, 2014b; Sargeant et al. 2015; Dudek et al. 2016). Modeled on the psychotherapeutic concept of a therapeutic alliance, the educational alliance framework may promote supportive relationships between learners and teachers resulting in meaningful feedback exchanges where learners feel comfortable disclosing their limitations and insecurities, and teachers ground their feedback in learner goals while being mindful of their fears and the context (Telio et al. 2015; Telio et al. 2016). Establishing such an alliance necessitates that residents and attendings have conversations that demonstrate the teacher's commitment to the learner and the learning process, and establish a relationship that permits disclosure, thus narrowing the "hidden" space. Faculty can acknowledge their own fears and limitations, demonstrate understanding of the learner's context and provide goal-directed feedback. Institutional interventions to enhance self-disclosure can include opportunities for creating longitudinal relationships, a climate that encourages admission of limitations and training in giving nonjudgmental feedback.

The last quadrant, the "unknown" space, is the most challenging to address because neither the resident nor their supervisors or peers are aware of these behaviors. 
These can include abilities or a limitation that a professional is unaware that they possess or skills that are underestimated. Shrinking this area would involve a multitude of approaches such as residents' readiness to discover new areas of self, direct performance observation by different supervisors and multisource feedback. Supervisors, peers and nonphysician team members, such as nurses or case managers and patients, are all likely to perceive and provide insights on different dimensions of performance, thus enhancing professional development of residents (Sargeant et al. 2005; Ten Cate and Sargeant 2011; Holmboe and Ross 2012; Sargeant 2015; van der Meulen et al. 2017). However, it has also been reported that physicians tend to view nonphysician sources of feedback as less credible and beneficial, therefore less receptive to their feedback (Sargeant et al. 2005, 2007; Ten Cate and Sargeant 2011). Institutions can promote these strategies by implementing formal interprofessional feedback, providing training in receiving and incorporating feedback into performance, and creating a culture of openness to self-discovery. With time, the combination of these strategies could shrink the unknown space.

This study has limitations which may have affected our findings. The inquiry was based at a single residency program, and the data may not be completely transferable to other programs and institutions. The data were not collected with the goal of exploring opinions about self-awareness or reflection, rather the analysis was performed on preexisting data using a framework-based qualitative approach. Focus groups aim to discover participants' opinions on a given subject, but such perceptions may differ from actions. While a large quantity of narratives was available, our participants were a sample of a larger resident population, and we may not have captured a full range of opinions from nonparticipants. To ensure rigor, our data sources included focus group transcripts, field notes and observations by two people, and independent data analysis by two or more investigators. The findings also appear to be consistent with existing literature on sociocultural factors that influence feedback (Shute 2008; Mann et al. 2011; Sargeant et al. 2009, 2011; Eva et al. 2012; Watling et al. 2013; van de Ridder et al. 2014; Watling 2014b). Our context is typical of large medicine residency programs and the findings are potentially transferable to similar postgraduate education settings. Finally, attention was paid to reflexivity in formulating open-ended study questions, data collection that allowed for group interactions and triangulation of data analysis.

\section{Suggestions for further research}

In this study, we have explored the perceptions of residents and faculty regarding the importance and influence of factors such as self-assessment and reflection on feedback seeking, receptivity and professional growth, through the lens of the Johari window model of self-awareness. Further research is required to investigate whether and how these strategies come into play during real-time feedback conversations. It is also important to explore whether increasing direct performance observation and designing longitudinal mentoring relationships will improve accurate self-assessment, disclosure and willingness to engage in self- discovery. Our next steps will include observations of realtime feedback conversations between faculty and residents using an ethnographic approach, followed by reflexive debriefing of feedback behaviors. Finally, we aim to design feedback training incorporating the Johari framework and study its impact on feedback behaviors of faculty and residents.

\section{Conclusions}

Informed self-assessment and facilitated reflection are integral aspects of feedback conversations. These strategies should incorporate data from self and multiple external sources. The Johari window, an established model for selfawareness in interpersonal communications, can provide a robust framework for teachers to plan feedback conversations as well as institutions to design feedback initiatives that enhance its quality and impact on professional growth. Normalizing disclosure of fears and limitations, encouraging feedback seeking, training in providing nonjudgmental feedback and providing opportunities for longitudinal relationships can enhance self-awareness and promote self-discovery which can ultimately maximize the "open" quadrant of the Johari window.

\section{Acknowledgements}

We express our appreciation to all the residents and faculty who participated in this study and provided valuable insights on this topic.

\section{Disclosure statement}

The authors reports no conflicts of interest. The authors alone are responsible for the content and writing of this article.

\section{Funding}

This research was funded by the Department of Medicine CERS (Clinical Education Research Scholars) grant at the Brigham and Women's Hospital.

\section{Glossary}

Johari window: Is a psychological matrix developed by Joseph Luft and Harry Ingham in 1955, to enable awareness and understanding of own behaviors, feelings and motivation during interpersonal interactions (Luft 1969).

Luft J. 1969. Of human interaction. Palo Alto (CA): National Press Books. 76084008

Reflexivity in Qualitative Research: Qualitative researchers need to be aware of their biases and assumptions and acknowledge how their relationship to the research topic and participants can influence data collection, analysis and reporting. This concept is termed reflexivity.

Watt D. On becoming a qualitative researcher: the value of reflexivity. TQR. 2016;12: 82-101.

\section{Notes on contributors}

Dr. Subha Ramani, MBBS, MMEd, MPH, is the Director of the Scholars in Medical Education Track for the Internal Medicine Residency 
Program at Brigham and Women's Hospital and Assistant Professor of Medicine at Harvard Medical School.

Dr. Karen Könings, PhD, is Associate Professor at the School of Health Professions Education, Maastricht University.

Dr. Karen Mann, PhD, (Late) was Professor Emeritus, Department of Medical Education, Faculty of Medicine at Dalhousie University, Halifax, Canada.

Dr. Cees van der Vleuten, PhD, is the Director of the School of Health Professions Education and Professor of Education, Department of Educational Development and Research, Faculty of Health, Medicine and Life Sciences, Maastricht University.

\section{References}

Bernabeo EC, Holtman MC, Ginsburg S, Rosenbaum JR, Holmboe ES 2011. Lost in transition: the experience and impact of frequent changes in the inpatient learning environment. Acad Med. 86:591-598.

Bok HG, Teunissen PW, Spruijt A, Fokkema JP, van Beukelen P, Jaarsma DA, van der Vleuten CP. 2013. Clarifying students' feedback-seeking behaviour in clinical clerkships. Med Educ. 47:282-291.

Boud D. 1995. Enhancing learning through self assessment. London; New York: RoutledgeFalmer.

Boud D. 2015. Feedback: ensuring that it leads to enhanced learning Clin Teach. 12:3-7.

Boud D, Keogh R, Walker D. 1985. Reflection, turning experience into learning. London; New York: Kogan Page; Nichols Pub.

Cantillon P, Sargeant J. 2008. Giving feedback in clinical settings. BMJ. 337:a1961.

Chaffey LJ, de Leeuw EJ, Finnigan GA. 2012. Facilitating students' reflective practice in a medical course: literature review. Educ Health. 25:198-203.

Charmaz K. 2014. Constructing grounded theory. 2nd ed. London; Thousand Oaks (CA): SAGE Publications.

Creswell JW. 2012. Educational research: planning, conducting, and evaluating quantitative and qualitative research. 4th ed. Boston: Pearson.

Creswell JW, Creswell JW. 2013. Qualitative inquiry and research design: choosing among five approaches. 3rd ed. Los Angeles: SAGE Publications.

Crommelinck M, Anseel F. 2013. Understanding and encouraging feedback-seeking behaviour: a literature review. Med Educ. 47:232-241.

Davis DA, Mazmanian PE, Fordis M, Van Harrison R, Thorpe $K E$, Perrier L. 2006. Accuracy of physician self-assessment compared with observed measures of competence: a systematic review. JAMA 296:1094-1102.

Delva D, Sargeant J, MacLeod T. 2011. Feedback: a perennial problem. Med Teach. 33:861-862.

Dudek NL, Dojeiji S, Day K, Varpio L. 2016. Feedback to supervisors: is anonymity really so important? Acad Med. 91:1305-1312.

Dunning D, Heath C, Suls JM. 2004. Flawed self-assessment: implications for health, education, and the workplace. Psychol Sci Public Interest. 5:69-106.

Ehrlinger J, Johnson K, Banner M, Dunning D, Kruger J. 2008. Why the unskilled are unaware: further explorations of (absent) self-insight among the incompetent. Organ Behav Hum Decis Process. 105:98-121.

Epstein RM, Hundert EM. 2002. Defining and assessing professional competence. JAMA. 287:226-235.

Eva KW, Regehr G. 2005. Self-assessment in the health professions: a reformulation and research agenda. Acad Med. 80:S46-S54.

Eva KW, Regehr G. 2007. Knowing when to look it up: a new conception of self-assessment ability. Acad Med. 82:S81-S84.

Eva KW, Regehr G. 2008. "I'll never play professional football" and other fallacies of self-assessment. J Contin Educ Health Prof. 28:14-19.

Eva KW, Armson H, Holmboe E, Lockyer J, Loney E, Mann K, Sargeant J. 2012. Factors influencing responsiveness to feedback: on the interplay between fear, confidence, and reasoning processes. Adv Health Sci Educ Theory Pract. 17:15-26.

Hayton A, Kang I, Wong R, Loo LK. 2015. Teaching medical students to reflect more deeply. Teach Learn Med. 27:410-416.
Holmboe E, Ginsburg S, Bernabeo E. 2011. The rotational approach to medical education: time to confront our assumptions? Med Educ 45:69-80.

Holmboe ES, Ross K. 2012. Commentary: realizing the formative potential of multisource feedback in regulatory-based assessment programs. Acad Med. 87:1657-1659.

Kennedy TJ, Lingard LA. 2006. Making sense of grounded theory in medical education. Med Educ. 40:101-108.

Kruger J, Dunning D. 1999. Unskilled and unaware of it: how difficulties in recognizing one's own incompetence lead to inflated self-assessments. J Pers Soc Psychol. 77:1121-1134.

Luft J. 1969. Of human interaction. Palo Alto (CA): National Press Books.

Mann K, van der Vleuten C, Eva K, Armson H, Chesluk B, Dornan T, Holmboe E, Lockyer J, Loney E, Sargeant J. 2011. Tensions in informed self-assessment: how the desire for feedback and reticence to collect and use it can conflict. Acad Med. 86:1120-1127.

Moon J. 2004. A handbook of reflective and experiential learning. London: RoutledgeFalmer.

Numerof RE. 1979. How assertive are you? A look through the Johari Window. Health Serv Manager. 12:7-9.

Patton MQ. 2002. Qualitative research and evaluation methods. 3rd ed. Thousand Oaks (CA): SAGE Publications.

Ramani S. 2016. Reflections on feedback: closing the loop. Med Teach. 38:206-207.

Ramani S, Mann K. 2016. Introducing medical educators to qualitative study design: twelve tips from inception to completion. Med Teach. 38:456-463.

Ramani S, Post SE, Konings K, Mann K, Katz JT, van der Vleuten C. 2017. "It's just not the culture": a qualitative study exploring residents' perceptions of the impact of institutional culture on feedback. Teach Learn Med. 29:153-161.

Sargeant J. 2008. 'To call or not to call': making informed self-assessment. Med Educ. 42:854-855.

Sargeant J. 2012. How external performance standards inform selfassessment. Med Teach. 34:267-268.

Sargeant J. 2015. Reflecting upon multisource feedback as 'assessment for learning'. Perspect Med Educ. 4:55-56.

Sargeant J, Lockyer J, Mann K, Holmboe E, Silver I, Armson H, Driessen E, MacLeod T, Yen W, Ross K, et al. 2015. Facilitated reflective performance feedback: developing an evidence- and theory-based model that builds relationship, explores reactions and content, and coaches for performance change (R2C2). Acad Med. 90:1698-1706.

Sargeant J, Mann K, Ferrier S. 2005. Exploring family physicians' reactions to multisource feedback: perceptions of credibility and usefulness. Med Educ. 39:497-504.

Sargeant J, Mann K, Sinclair D, van der Vleuten C, Metsemakers J. 2007. Challenges in multisource feedback: intended and unintended outcomes. Med Educ. 41:583-591.

Sargeant J, Mann K, Sinclair D, Van der Vleuten C, Metsemakers J. 2008a. Understanding the influence of emotions and reflection upon multi-source feedback acceptance and use. Adv Health Sc Educ Theory Pract. 13:275-288.

Sargeant J, Mann K, van der Vleuten C, Metsemakers J. 2008b. "Directed" self-assessment: practice and feedback within a social context. J Contin Educ Health Prof. 28:47-54.

Sargeant JM, Mann KV, van der Vleuten CP, Metsemakers JF. 2009. Reflection: a link between receiving and using assessment feedback. Adv Health Sci Educ Theory Pract. 14:399-410.

Sargeant J, McNaughton E, Mercer S, Murphy D, Sullivan P, Bruce DA. 2011. Providing feedback: exploring a model (emotion, content, outcomes) for facilitating multisource feedback. Med Teach. 33:744-749.

Schoin DA. 1983. The reflective practitioner: how professionals think in action. New York: Basic Books.

Schumacher DJ, Englander R, Carraccio C. 2013. Developing the master learner: applying learning theory to the learner, the teacher, and the learning environment. Acad Med. 88:1635-1645.

Shute V. 2008. Focus on formative feedback. Rev Educ Res 78:153-189.

Sutherland JA. 1995. The Johari Window: a strategy for teaching therapeutic confrontation. Nurse Educ. 20:22-24.

Telio S, Ajjawi R, Regehr G. 2015. The "educational alliance" as a framework for reconceptualizing feedback in medical education. Acad Med. 90:609-614. 
Telio S, Regehr G, Ajjawi R. 2016. Feedback and the educational alliance: examining credibility judgements and their consequences. Med Educ. 50:933-942.

Ten Cate OT. 2013. Why receiving feedback collides with self determination. Adv Health Sci Educ Theory Pract. 18:845-849.

Ten Cate OT, Sargeant J. 2011. Multisource feedback for residents: how high must the stakes be? J Grad Med Educ. 3:453-455.

Teunissen PW, Bok HG. 2013. Believing is seeing: how people's beliefs influence goals, emotions and behaviour. Med Educ 47:1064-1072.

Teunissen PW, Stapel DA, van der Vleuten C, Scherpbier A, Boor K, Scheele F. 2009. Who wants feedback? An investigation of the variables influencing residents' feedback-seeking behavior in relation to night shifts. Acad Med. 84:910-917.

van de Ridder JM, Berk FC, Stokking KM, Ten Cate OT. 2014. Feedback providers' credibility impacts students' satisfaction with feedback and delayed performance. Med Teach. 13:1-8.

van der Meulen MW, Boerebach BC, Smirnova A, Heeneman S, Oude Egbrink MG, van der Vleuten CP, Arah OA, Lombarts KM. 2017. Validation of the INCEPT: a multisource feedback tool for capturing different perspectives on physicians' professional performance. J Contin Educ Health Prof. 37:9-18.

VandeWalle D, Cron WL, Slocum JW Jr. 2001. The role of goal orientation following performance feedback. J Appl Psychol. 86:629-640.

VandeWalle D, Ganesan S, Challagalla GN, Brown SP. 2000. An integrated model of feedback-seeking behavior: disposition, context, and cognition. J Appl Psychol. 85:996-1003.

Verklan MT. 2007. Johari window: a model for communicating to each other. J Perinat Neonatal Nurs. 21:173-174.

Watling CJ. 2014a. Cognition, culture, and credibility: deconstructing feedback in medical education. Perspect Med Educ. 3:124-128.

Watling CJ. 2014b. Unfulfilled promise, untapped potential: feedback at the crossroads. Med Teach. 36:692-697.

Watling CJ, Lingard L. 2012. Grounded theory in medical education research: AMEE Guide No. 70. Med Teach. 34:850-861.

Watling CJ, Driessen $E$, van der Vleuten $C P$, Vanstone $M$, Lingard L. 2013. Beyond individualism: professional culture and its influence on feedback. Med Educ. 47:585-594.

Watt D. 2007. On becoming a qualitative researcher: the value of reflexivity. TQR. 12:82-101. 